\title{
Ambient Air Pollution and Atherosclerosis: Recent Updates
}

\author{
Graham H. Bevan ${ }^{1,2}$ (1) Sadeer G. Al-Kindi ${ }^{1,2,3} \cdot$ Robert Brook $^{4}$ - Sanjay Rajagopalan ${ }^{1,2,3}$
}

Accepted: 2 July 2021 / Published online: 21 August 2021

(C) The Author(s), under exclusive licence to Springer Science+Business Media, LLC, part of Springer Nature 2021

\begin{abstract}
Purpose of Review During the past century, exposure to particulate matter (PM) air pollution $<2.5 \mu \mathrm{m}$ in diameter $\left(\mathrm{PM}_{2.5}\right)$ has emerged as an all-pervading element of modern-day society. This increased exposure has come at the cost of heightened risk for cardiovascular (CV) morbidity and mortality. Not only can short-term $\mathrm{PM}_{2.5}$ exposure trigger acute $\mathrm{CV}$ events in susceptible individuals, but longer-term exposure over years augments $\mathrm{CV}$ risk to a greater extent in comparison with short-term exposure. The purpose of this review is to examine the available evidence for how ambient air pollution exposure may precipitate events at various time frames.

Recent Findings Recent epidemiological studies have demonstrated an association between ambient $\mathrm{PM}_{2.5}$ exposure and the presence and progression of atherosclerosis in humans. Multiple animal exposure experiments over two decades have provided strong corroborative evidence that chronic exposure in fact does enhance the progression and perhaps vulnerability characteristics of atherosclerotic lesions.

Summary Evidence from epidemiological studies including surrogates of atherosclerosis, human translational studies, and mechanistic investigations utilizing animal studies have improved our understanding of how ambient air pollution may potentiate atherosclerosis and precipitate cardiovascular events. Even so, future research is needed to fully understand the contribution of different constituents in ambient air pollution-mediated atherosclerosis as well as how other systems may modulate the impact of exposure including adaptive immunity and the gut microbiome. Nevertheless, due to the billions of people continually exposed to $\mathrm{PM}_{2.5}$, the long-term pro-atherosclerotic effects of this ubiquitous air pollutant are likely to be of enormous and growing global public health importance.
\end{abstract}

Keywords Atherosclerosis · Ambient air pollution

\section{Introduction}

Anthropogenic pollution is a pervasive element of modern-day society and historically an obligate byproduct of every facet of daily living: everything from cooking and commuting to industry. Air pollution is a heterogeneous amalgam of gases,

The article is part of the Topical Collection on Coronary Heart Disease

Sanjay Rajagopalan

sxr647@case.edu

1 Department of Medicine, University Hospitals Cleveland Medical Center, Cleveland, OH, USA

2 Case Western Reserve University School of Medicine, Cleveland, $\mathrm{OH}$, USA

3 Harrington Heart and Vascular Institute, University Hospitals, Cleveland, $\mathrm{OH}$, USA

4 School of Medicine, Wayne State University, Detroit, MI, USA particulate matter (PM), and miscellaneous constituents (e.g., metals, organic and elemental carbon compounds, nitrates, sulfates) in both particulate and gaseous phase [1]. While both particulate pollutants and gaseous components are linked to human disease, the evidence is strongest for the PM component and especially for cardiovascular (CV) risk. The particles range in aerodynamic diameter from less than $0.1 \mu \mathrm{m}$ in diameter (ultrafine PM; $0.001-0.1 \mu \mathrm{m}$ ) to particles up to $10 \mu \mathrm{m}$ in size (coarse PM; $\mathrm{PM}_{10}$ ) (Fig. 1). The greatest body of evidence to date has implicated $\mathrm{PM}<2.5 \mu \mathrm{m}\left(\mathrm{PM}_{2.5}\right.$; fine $\left.\mathrm{PM}\right)$ in diameter, about $1 / 50^{\text {th }}$ the size of a human hair and roughly 20 times the size of the coronavirus disease 2019 (COVID-19) viral particle with CV risk [2-4]. This review summarizes some of the controversies and questions in the area of air pollution and atherosclerosis, particularly around the time scales of exposure that are relevant, the human epidemiological evidence, the underlying biological mechanisms and concludes with a discussion on the challenges and opportunities in the field. 
A

\section{NAAQS Annual Limit (12) NAAQS Daily Limit (35)}
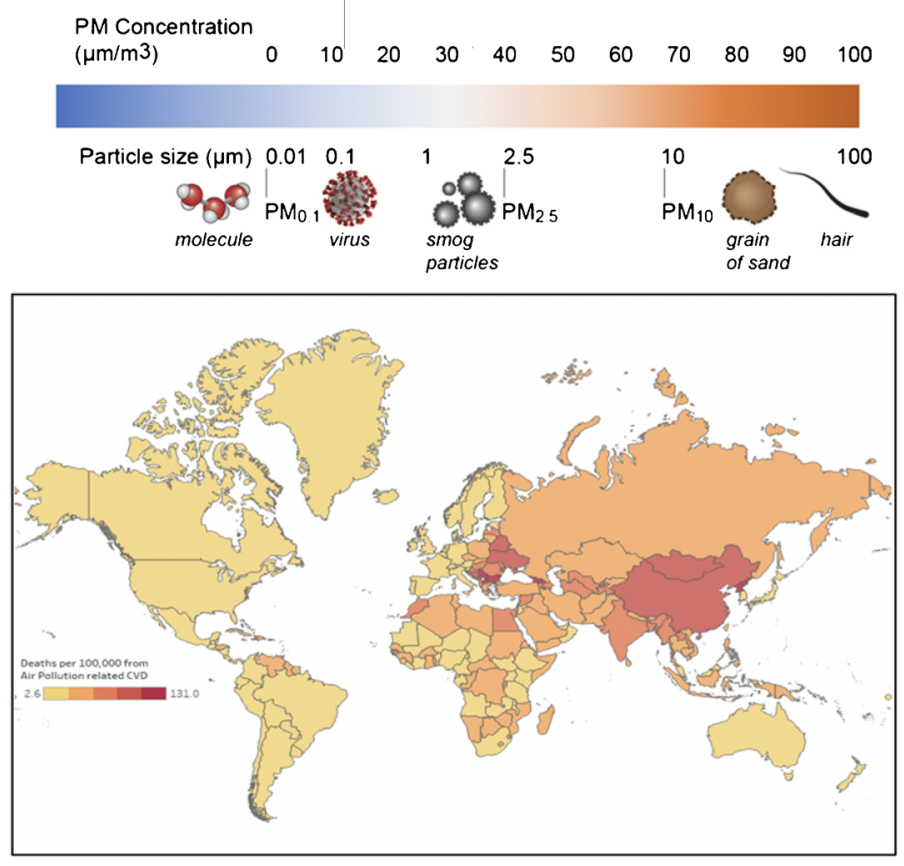
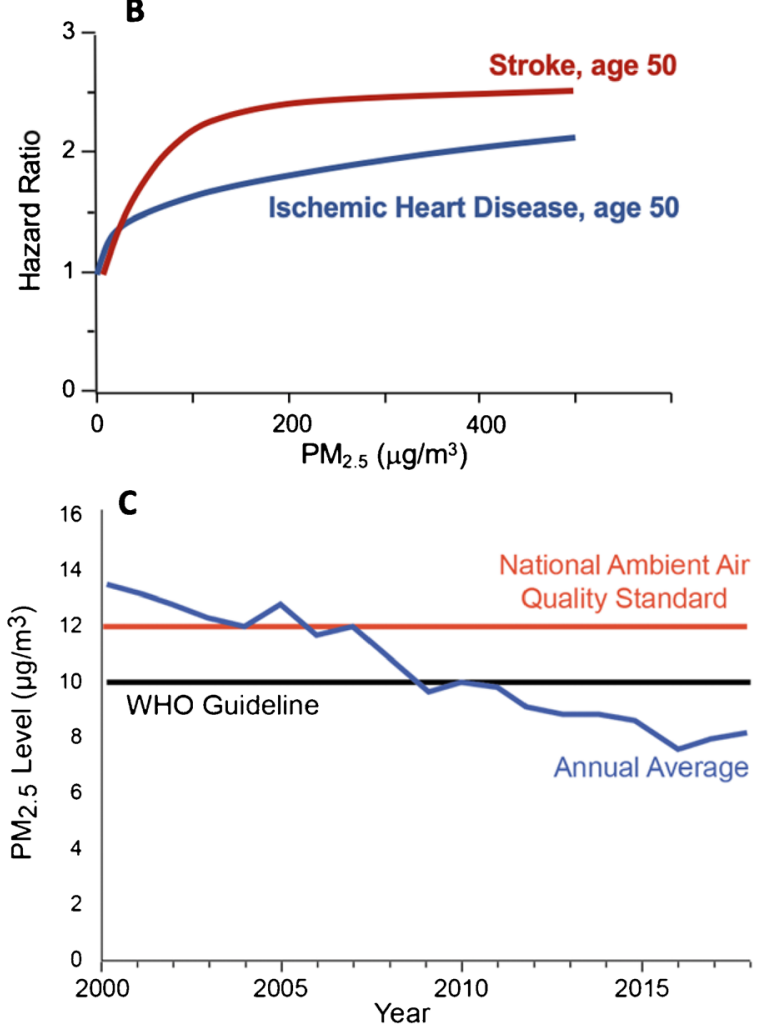

Fig. 1 A Particulate matter air pollution and National Ambient Air Quality Standards (NAAQS). The world map represents a heat map of deaths per 100,000 attributable to $\mathrm{PM}_{2.5}$ air pollution in 2019. Data from Global Burden of Disease Study 2019. The Institute of Health Metrics and Evaluation, Seattle WA, 2020. B Exposure-response relationship for stroke and ischemic heart disease modeled for a 50-year-old adult. The response function represents a meta-regressed Bayesian, regularized, trimmed (MR-BRT) curve derived by relaxing the log-linear assumption using cubic splines (extracted from the Institute for Health

\section{What Are Air Pollution Regulation Thresholds and Sources Responsible for CV Events?}

It has been 57 years since the US Congress passed the first Clean Air Act in 1963 with the National Ambient Air Quality Standards (NAAQS) being enacted in 1970. The NAAQS, last updated in 2010, specify standards for multiple pollutants including particulate matter, both $\mathrm{PM}_{10}$ and $\mathrm{PM}_{2.5}$. The current NAAQS threshold for $\mathrm{PM}_{2.5}$ is $12 \mu \mathrm{g} / \mathrm{m}^{3}$ for annual average concentrations, and $35 \mu \mathrm{g} / \mathrm{m}^{3}$ for daily averages (Fig. 1) [5]. Multiple studies however continue to show robust health effects even at levels well below the NAAQS. Among the gaseous pollutants, ozone has well-established health effects $[1,4,6 \bullet \bullet, 7]$. Although the current NAAQS is $70 \mathrm{ppb}$ averaged over 8 hours, several epidemiological studies have reported an increased risk of cardiopulmonary disease and mortality at levels $<70 \mathrm{ppb}[8,9]$.

The NAAQS sets standards for pollutants for which there is adequate evidence of a relationship to human disease. However, the strength of association to human disease is
Metrics and Evaluation (IHME). GBD Compare. Seattle, WA: IHME, University of Washington, 2015). Available from http://vizhub. healthdata.org/gbd-compare. (accessed February 12, 2021) [59]. C Average population-weighted $\mathrm{PM}_{2.5}$ concentrations in the USA, China, and India. $\mathrm{PM}_{2.5}$ estimates are derived using a blended model that combines satellite observations, global chemical transport models, and ground level data from 10,408 monitors representing urban and rural data in 116 countries. To derive population-weighted averages, $\mathrm{PM}_{2.5}$ levels adjusted by population size

facilitated by the ease of measurement of the pollutant, with bias towards less evidence for particles that are more difficult to characterize. One of the reasons for the abundant literature on fine $\mathrm{PM}_{2.5}$ is therefore the fact that these particles are easy to measure given their stability over an extended penumbra, encompassing large geographic regions $[3,4,10]$. Recently, there is burgeoning evidence that ultrafine PM (PM between 0.001 and $0.1 \mu \mathrm{m}$ in size), typically arising from traffic and diesel emissions, may pose significant hazards to cardiovascular (CV) health. However, the fact that these particles are short lived, typically existing only within a few hundred meters of a combustion source, has made exposure-response studies challenging [1].

The chemical composition is important to consider in relation to oxidative stress potential, solubility, lung deposition, and stability. Primary pollutants, released into the troposphere, form secondary pollutants in the atmosphere. Ultrafine PM typically originates from combustion sources, whereas coarse PM (PM between 2.5 and $10 \mu \mathrm{m}$ in size; $\mathrm{PM}_{10}$ ) may derive from non-combustion sources such as agriculture or erosion. 
Ozone $\left(\mathrm{O}_{3}\right)$ is the most common secondary pollutant, but other volatile and semi-volatile organic compounds can be found in either gas or particle phase. Several lines of existing evidence support that transition metals, secondary organic aerosols, semi-quinones, and other components of $\mathrm{PM}_{2.5}$ are likely relevant in relation to oxidative stress potential and promotion of CV events. A recent study found that secondary inorganic components, crustal material, and secondary biogenic organic aerosols control the mass concentration of particulate matter. By contrast, oxidative potential concentration is associated mostly with anthropogenic sources, in particular with fine-mode secondary organic aerosols largely from residential biomass burning and coarse-mode metals from vehicular non-exhaust emission [11]. Characteristics of UFP such as high surface area, particle number, metal, and organic carbon content suggest that they may confer higher CV risk even after short-term exposure, although definitive evidence is lacking [12]. While the preponderance of research has focused on size fractions, which is reflected in national pollution standards, source information could be quite impactful for formulating effective air quality policies. A sizeable portion of the world's population, for example, lives close (within $500 \mathrm{~m}$ ) to roads and automotive traffic and is therefore exposed to elevated concentrations. Human behavior also impacts exposure since the average resident of Western countries above the age of 15 spends 55 minutes each day traveling in motor vehicles [13]. Additional sources that could be of regional importance include agricultural emissions including crop burning in certain parts of the world. Recently, climate-related extreme events have become sources of high levels. Wildfires, for instance, may have contributed to a recent observed increase in pollution levels in the USA, a reversal of a decades long trend of decreasing ambient air pollution [14].

\section{What Is the Relationship Between Air Pollution Levels and Cardiovascular Events?}

Over the past three decades, numerous publications worldwide have shown that exposure to $\mathrm{PM}_{2.5}$ is associated with an increased risk for myocardial infarction, stroke, and CV mortality (Fig. 1). In time series and case-crossover studies in the USA, Canada, and Europe, short-term elevations at levels $<35 \mu \mathrm{g} / \mathrm{m}^{3}$ translate to $\mathrm{a} \approx 0.25-1 \%$ elevation in relative risk for CV-related mortality/10 $\mu \mathrm{g} / \mathrm{m}^{3}$ of $\mathrm{PM}_{2.5}[1,15] \mathrm{At}$ daily levels $>35 \mu \mathrm{g} / \mathrm{m}^{3}$, a meta-analysis of 7 studies in China showed an increase of $0.35 \% / 10 \mu \mathrm{g} / \mathrm{m}^{3}$ in risk for CV mortality [16]. Chronic exposure studies have generally shown much more robust estimates consistent with the idea that cumulative exposure to $\mathrm{PM}_{2.5}$ confers magnified effects, analogous to exposure to classic risk factors like LDL-C or smoking over long periods. In the American Cancer Society (1.2 million people in the USA) after adjustment of 44 variables, each
$10 \mu \mathrm{g} / \mathrm{m}^{3}$ increment in annual $\mathrm{PM}_{2.5}$ was associated with $15 \%$ relative increase in ischemic heart disease (IHD) deaths (HR $1.15,1.11-1.20$ ) [17]. Much more robust estimates are seen at low exposure levels in Canada (mean $\mathrm{PM}_{2.5}$ of $8.7 \mu \mathrm{g} / \mathrm{m}^{3}$, $31 \%$ relative increase in IHD death (HR $1.31 / 10 \mu \mathrm{g} / \mathrm{m}^{3}$ increment in annual $\mathrm{PM}_{2.5}$ ) [18]. Similar estimates are seen in China at dramatically higher levels suggesting continuing robust effects at extreme doses of $\mathrm{PM}_{2.5}$ [19]. In fact, a recent integrated exposure response function suggests a near linear relationship [6••]. However, despite the possibility that risk could accrue over a lifetime, in practice, much of the attributable risk in epidemiologic studies of chronic exposure is in the first 1-2 years. This is likely due to the fact that air pollution levels in the years prior to an event are likely highly correlated with exposures over many years, and thus a year of exposure may be enough to understand the risk over decades.

Both time series and case-crossover studies have shown an association between $\mathrm{PM}_{2.5}$ exposure and the risk of non-fatal MI (ESM Table 1) [4]. The evidence is stronger for STEMI compared to NSTEMI. Additionally, patients with angiographic evidence of coronary artery disease appear to be more susceptible to $\mathrm{PM}_{2.5}$ exposure [20]. In a meta-analysis of 34 studies, every $10 \mu \mathrm{g} / \mathrm{m}^{3}$ of $\mathrm{PM}_{2.5}$ (lag 0 day) was associated with a $2.5 \%$ relative risk for MI (RR, 1.025 ; 95\% CI: 1.015 1.036) with risk associations noted for other gaseous co-pollutants [21]. A 2019 meta-analysis of 80 studies found a $1 \%$ increase in stroke per $10 \mu \mathrm{g} / \mathrm{m}^{3}$ increment of short-term $\mathrm{PM}_{2.5}$ exposure and a $14 \%$ increase with chronic exposure. Associations were strongest for ischemic and hemorrhagic stroke [22].. Heart failure hospitalizations and death have also been well associated in a meta-analysis of 35 studies showing a $2.12 \%$ increase after short-term exposure to $10 \mu \mathrm{g} / \mathrm{m}^{3}(95 \%$ CI: 1.42-2.82) [23]. In a recent study among 23,302 heart failure patients examining health effects in a hospitalized population in North Carolina, a $1 \mu \mathrm{g} / \mathrm{m}^{3}$ increase in annual $\mathrm{PM}_{2.5}$ was associated with an elevated risk of all-cause mortality (hazard ratio $1.13 ; 95 \% \mathrm{CI}, 1.10-1.15$ ). Individuals living in areas above the NAAQS threshold had nearly 2-fold higher risk for mortality when compared with those below the threshold [24]. These relationships appear to remain true even when accounting for socioeconomic status, and in fact, associations may be stronger in lower socioeconomic status communities $[25,26,27 \bullet]$.

In contrast to $\mathrm{PM}_{2.5}$, the association between long-term ozone exposures and cardiovascular mortality is modest and lower than other causes of mortality, including COPD [28]. In the National Particle Component Toxicity (NPACT) Initiative, fossil fuel combustion source categories were most consistently associated with both short- and long-term adverse effects of $\mathrm{PM}_{2.5}$ exposure [29]. Sulfates, organic carbon, and nitrate components from fossil fuel combustion seem to have the most consistent association with increased cardiovascular risk [30]. An analysis of 445,860 adults enrolled in the 
American Cancer Society Cancer Prevention Study II (ACS-CPS II) showed that association between coal combustion $\mathrm{PM}_{2.5}$ was five times stronger than overall $\mathrm{PM}_{2.5}$ mass for IHD mortality [31].

\section{What Do Surrogate Studies in Atherosclerosis Tell Us?}

Multiple surrogates of atherosclerosis including carotid intima-media thickness, coronary artery calcium, coronary artery computed tomography angiography (CTA), and abdominal calcium can provide a window into the association between air pollution exposure and atherosclerotic disease and can be used to address mechanisms (ESM Table 2). Such studies primarily utilize a cross-sectional design, and thus their findings should be interpreted with caution, given the many limitations inherent to this type of analysis, which include significant potential for confounding variables. Nevertheless, errors in long-term exposure estimation or assignment have been shown to typically cause a bias towards the null hypothesis, rather than a positive association. The majority of published works do show a link between air pollution exposure and surrogates for atherosclerosis.

Coronary artery calcification (CAC) is perhaps the best direct surrogate for atherosclerosis and has been shown by multiple studies to be a strong predictor for future cardiovascular events, in contrast to other surrogates such as CIMT, abdominal aortic calcium, and endothelial function [32]. The best longitudinal analysis of $\mathrm{PM}_{2.5}$ exposure and its association with $\mathrm{CAC}$ is from the Multi-Ethnic Study of Atherosclerosis (MESA). In MESA-Air, coronary artery calcium change by CT measured in 6795 participants throughout the MESA study on 2 or more occasions in subjects aged 45-84 years in six metropolitan areas in the USA were correlated with air pollutant measurements. For each $5 \mu \mathrm{g} \mathrm{PM} \mathrm{PM}_{2.5} / \mathrm{m}^{3}$, coronary calcium progressed by 4.1 Agatston units/year (95\% CI 1.4-6.8) and for each 40 ppb nitrogen oxides $\left(\mathrm{NO}_{\mathrm{x}}\right)$, coronary calcium progressed by 4.8 Agatston units per year (0.9-8.7). At baseline, coronary artery calcium scores were 145 Agatston units, with calcium score increasing by 24 Agatston units per year (SD 58) [33]. These estimates were robust and given the exceptional characterization of patients in MESA, likely reliable. Even in such a well-characterized cohort, residual confounding is, however, hard to exclude. Though CAC was strongly associated with $\mathrm{CV}$ events, the increase in coronary calcium is a surrogate for other features of plaque vulnerability such as thin fibrous cap, lipid core, inflammation, presence of healed disruptions, and plaque angiogenesis. Plaques with high calcium tend to progress faster and thus may be identified by the burden of atherosclerosis or its progression. Thus, even a robust surrogate such as CAC progression may not accurately represent a mechanism by which risk of $\mathrm{PM}_{2.5}$ for CVD is mediated, but rather is a signpost for other mechanisms. A recent paper from
South Korea characterized plaque development using coronary computed tomography angiography performed at least 2 years apart. An increase in $\mathrm{PM}_{2.5}$ concentration was associated with increased risk of developing high-risk plaque (defined by attenuation, calcium, and remodeling) with an adjusted hazard ratio of 1.62 (95\% CI: $1.22-2.15) . \mathrm{PM}_{2.5}$ was also associated with the development of fibrofatty or necrotic core components in addition to greater plaque volume [34•].

\section{What Do Time Scales of Exposure Tell Us About the Mechanisms of Air Pollution-Mediated Cardiovascular Events?}

Air pollution exposure is ubiquitous and indeed occurs over a lifetime of chronic steady exposure in most parts of the world. Within this background of ubiquitous chronic exposure, are short-term fluctuations within days to weeks even pertinent? The commonly used approach in air pollution epidemiology is to link metrics of long-term: yearly or short-term, daily/weekly exposures with events. These time windows are chosen partly because they are convenient and readily available. Lifelong exposure windows currently are not feasible, at least in the USA as the Environmental Protection Agency started maintaining air pollution exposure inventories that include $\mathrm{PM}_{2.5}$ only since 1998, which would provide a temporal window of 22 years of exposure at best. Clearly, even if one were to be born in 1998, this may not be an adequate time frame for vulnerable plaque to develop within the background of atherosclerosis for individuals with a lipoprotein and risk factor profile similar to most North Americans.

Epidemiological associations between $\mathrm{CV}$ events and $\mathrm{PM}_{2.5}$ exposure have difficulty differentiating the effect of short-term and long-term exposures since individuals exposed to high levels of air pollution for short periods of time are more likely to experience chronically elevated $\mathrm{PM}_{2.5}$ levels. Nevertheless, chronic exposure may promote the development of an underlying disease state that enhances future risk for $\mathrm{CV}$ events, which may then precipitate with short-term elevations in $\mathrm{PM}_{2.5}$. Hypertension is a common risk factor that may behave similarly to long-term $\mathrm{PM}_{2.5}$ exposures. Chronic increases in blood pressure are well known to increase risk for future coronary heart disease. However, there is an equally strong epidemiology of blood pressure-mediated short-term events, whereby even small elevations in acute blood pressure can trigger coronary and cerebrovascular events.

From a biologic standpoint, chronic exposure windows may indeed be highly relevant in terms of progression of atherosclerosis and indeed may work like other conventional risk factors in increasing the risk for acute events. However, a chronic window of steady exposure may also facilitate components of vulnerability. The whole concept of vulnerability mandates that a series of events spatially clustered around a singular time point collude to 
determine a stochastic event. In the case of air pollution, this would typically mean an acute variation or spike in air pollution level over and above chronic persistent levels (Fig. 2). Thus, it is the acute spike in air pollution over hours or days that may be causally related to the acute event, but this does not preclude the importance of chronic exposure in the genesis of the very lesion that became "vulnerable." The association seen with time series analysis or case-crossover studies where acute alterations in air pollution levels over hours or days closely correlate with acute myocardial infarction is illustrative of the strong causal role of air pollution in acute myocardial infarction or cardiovascular death.

\section{Who Are Susceptible to Air Pollution's Effects? A Contemporary Reinterpretation of Harvesting in Air Pollution Studies}

The concept of "harvesting" is often invoked in air pollution studies to suggest exposure may preferentially cause the old and infirm to die. Prior statistical experiments were conducted to support the concept that air pollution does not merely affect the elderly and infirm but may indeed catastrophically strike individuals who were previously not thought to be at "risk." Air pollution may indeed contribute to "harvesting" in the sense that it may affect asymptomatic (not only old and infirm) but younger at-risk individuals. This may include those with subclinical cardiovascular disease or multiple risk factors who may succumb to an episode of acute elevation in $\mathrm{PM}_{2.5}$ (Fig. 2). Thus, it is indeed correct to state that sub-acute variations in air pollution exposure prior to an incipient event may really be the time window that matters from a biologic standpoint for acute events and what accounts for the preponderant portion of the risk. This does not mean that chronic time windows are not relevant in the genesis of the atherosclerosis in response to chronic $\mathrm{PM}_{2.5}$ exposure, or indeed in the genesis of the lesion that leads to an acute event. In support of these findings, multiple animal studies comparing filtered air to particulate matter exposure have corroborated that chronic PM exposures enhance the progression and vulnerability of atherosclerotic lesions (ESM Table 1) [1, 9-13]. Hence, it is possible that long-term exposure to ambient concentrations of $\mathrm{PM}_{2.5}$ may facilitate the transition to more vulnerable lesion formation in humans that may account for magnified risks.

\section{How Can Intervention Studies Inform Us on What Exposure Time Windows Are Relevant?}

There are a myriad number of factors that may confound studies designed to explore what time frames are relevant for exposure in the development of $\mathrm{CV}$ disease. Thus, alternate ways of approaching study design may be warranted. An acute controlled intervention by reducing air pollution levels using personal devices such as air pollution filters in vulnerable high-risk patients may be one way to test this hypothesis but would require strict adherence to any exposure reduction intervention. A reduction in events in short-term intervention trials can readily imply that short-term time exposure windows are causally related to events. Long-term cohort studies with better surrogate markers of atherosclerosis progression or imaging-based measures of vulnerability (FDG-PET or Na-F imaging) can further shed light on the importance of chronic exposure in facilitating progression of plaque or transition to a vulnerable phase. We and others have articulated the need for such trials from a public health perspective especially with the ready availability of devices to lower exposure levels both indoors and outdoors [35-37]. Indeed COVID-19 has vastly increased the social acceptability of masks and in most
Fig. 2 Conceptual model demonstrating how acute and chronic exposures enhance potential for cardiovascular events. Chronic exposure of decades may result in progression of atherosclerosis and the development of vulnerable disease state while acute rises in air pollution levels themselves may precipitate events. Adapted from Bevan GH, Al-Kindi S, Brook RD, Münzel T and Rajagopalan S. Ambient air pollution and atherosclerosis: insights into dose, time, and mechanisms. Arterioscler Thromb Vasc Biol. 2020: Atvbaha120315219 [3]

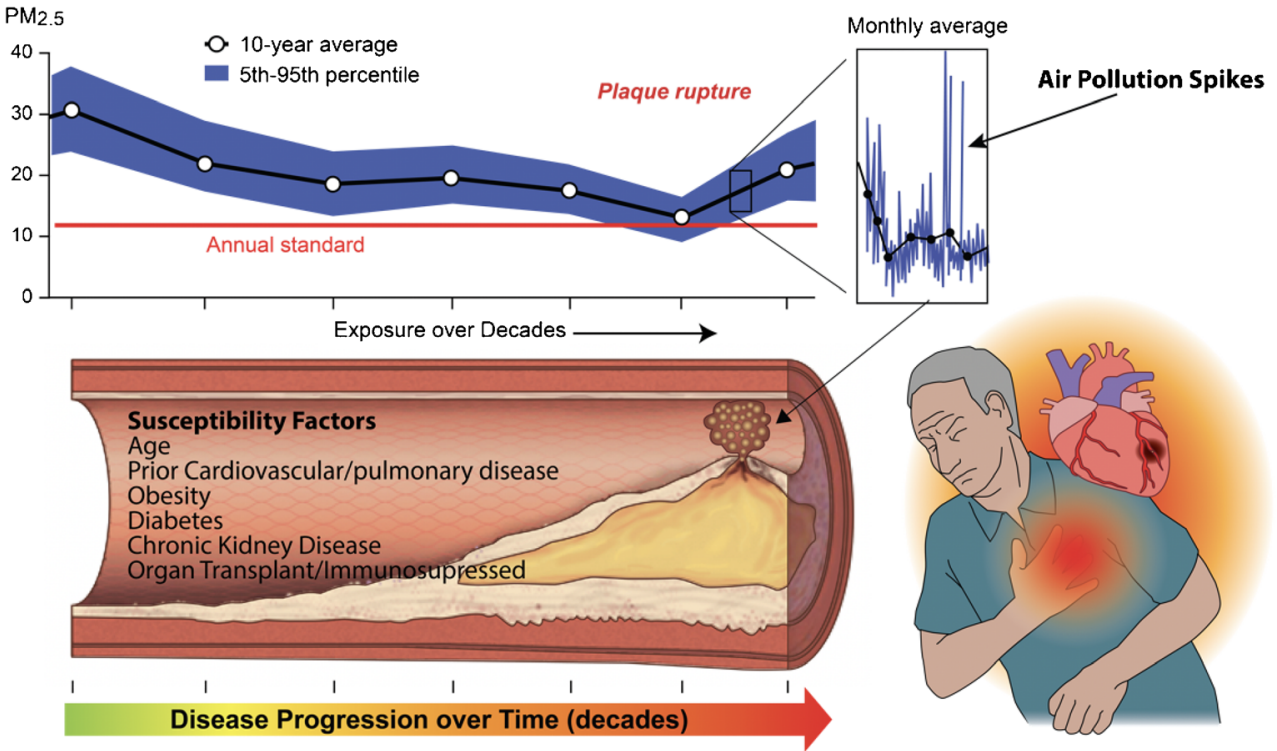


environments, now it may be practically challenging to design an outdoor mask intervention to lower $\mathrm{PM}_{2.5}$ levels given the ubiquitous use of mask for COVID-19 prevention. A recently published proceedings of a National Institutes of Health symposium reviewed the necessary considerations for intervention trials including sample size and effect estimates to demonstrate an effect [37].

\section{What Insights on Mechanisms Have Been Gleaned from Controlled Exposure Studies?}

Air pollution exposure has been implicated in multiple stages of the atherosclerosis process including early changes in vascular tone through redox alterations, inflammatory migration of subpopulations of innate immune cells, activation of immune responses, modification of cholesterol resulting in their uptake by innate immune cell populations, and finally progression of atherosclerosis including facilitation of pro-thrombotic responses (Fig. 3). A number of animal studies have provided mechanistic insight into how $\mathrm{PM}_{2.5}$ potentiates atherosclerotic disease (ESM Table 3).

\section{Oxidant Stress and Alterations in Vascular Tone}

Diminished exposure to $\mathrm{PM}_{2.5}$ and ultrafine particles such as diesel exhaust has been shown to alter nitric oxide bioavailability and increase vascular redox stress in both animals and humans [38]. Air pollution has also been shown to be associated with increased arterial stiffness, impaired conduit artery flow-mediated dilation, resistance in arteriolar dysfunction, and retinal artery changes [39]. In the majority of controlled-exposure human studies, short-term inhalational exposure to concentrated $\mathrm{PM}_{2.5}$ or diesel exhaust has been shown to result in reversible endothelial dysfunction in hours, reflected by reduction in flow or agonist-mediated vasodilation and release of vasoconstrictor factors such as endothelin-1 and matrix metalloproteinases [38, 39]. These early alterations indeed alter vascular hemodynamics and result in redox tone changes that could be pro-thrombogenic. In patients with coronary artery disease, exercise-induced ST segment depression and ischemic burden were also observed to be significantly higher during diesel exhaust exposure compared with filtered air exposure [40]. Another mechanism of vascular dysfunction may relate to depletion of endothelial progenitor cells, which could explain the vascular remodeling effects of long-term exposure to PM and has been described in both animals and human panel studies [41, 42]..

\section{Inflammation}

Exposure to $\mathrm{PM}_{2.5}$ causes enhanced inflammation through a number of different mechanisms. There are several experimental studies demonstrating an effect of lung macrophages in contributing to the elicitation of a systemic innate inflammatory response through the release of inflammatory cytokines and chemokines into the circulation $[43,44]$. Indeed bone marrow efflux of inflammatory Ly $6^{\text {hi+ }}$ monocytes has been demonstrated in response to chronic $\mathrm{PM}_{2.5}$ exposure which may result in infiltration of organs such as adipose and vasculature [45]. Toll-like receptor 4 (TLR4) appears to be critical to sensing $\mathrm{PM}_{2.5}$, as deficiency of TLR4 diminished the effect of $\mathrm{PM}_{2.5}$ in elicitation of these cells and abolition of tissue infiltration [44]. Several human cohort studies have also demonstrated a release of several inflammatory markers (e.g., C-reactive protein, interleukin-6, and tissue necrosis factor-alpha), but this has not always been consistent [46-49]. C-C chemokine receptor type 2 (CCR2) and chemokine (C-X-C motif) receptor 3 appear to be involved in the inflammatory response to chronic $\mathrm{PM}_{2.5}$ through distinct monocyte and T-cell-mediated pathways. CCR2 $2^{-/-}$ mice demonstrated a reduction in adipose inflammation, improved whole-body insulin resistance, and hepatic lipid accumulation in the liver [50].

\section{Oxidatively Modified Pro-atherogenic Products}

Oxidized phospholipids and cholesterol products have been shown to mediate inflammatory effects $\mathrm{PM}_{2.5}$ inhalation and may play a role in potentiation of atherosclerosis [51]. Oxidized phospholipids such as 1-palmitoyl-2-arachidonyl-sn-glycero-3-phosphorylcholine may facilitate recruitment of inflammatory cells, synthesis of cytokines, and enhancement of oxidative stress in the vasculature through established TLR4, NADPH-oxidase (NOX2), and neutrophil cytosolic factor 1 (NCF1) pathways, disruption of which reduces vascular inflammation in response to $\mathrm{PM}_{2.5}$ inhalation [44]. CD36 may be an important pathway in $\mathrm{PM}_{2.5}$-related vascular inflammation as 7-ketocholesterol forms in response to $\mathrm{PM}_{2.5}$ exposure and functions as an important mediator of endothelial dysfunction, thrombosis, and atherosclerosis [51]. Though clearly the lungs interface with pollution inhalation, the gastrointestinal tract may also be important as peroxidation product formation in intestines and the gastrointestinal tract in response to ultrafine PM could also induce inflammation and potentiate other pathways [52]. The contribution of biologic intermediates in inflammation resolution in response to air pollution in helping minimize inflammation remains an area of knowledge deficiency.

\section{Progression of Atherosclerosis}

Progression of atherosclerosis has been noted in a number of susceptible models including LDL receptor knockout $\left(\mathrm{LDLR}^{-/}\right)$ 


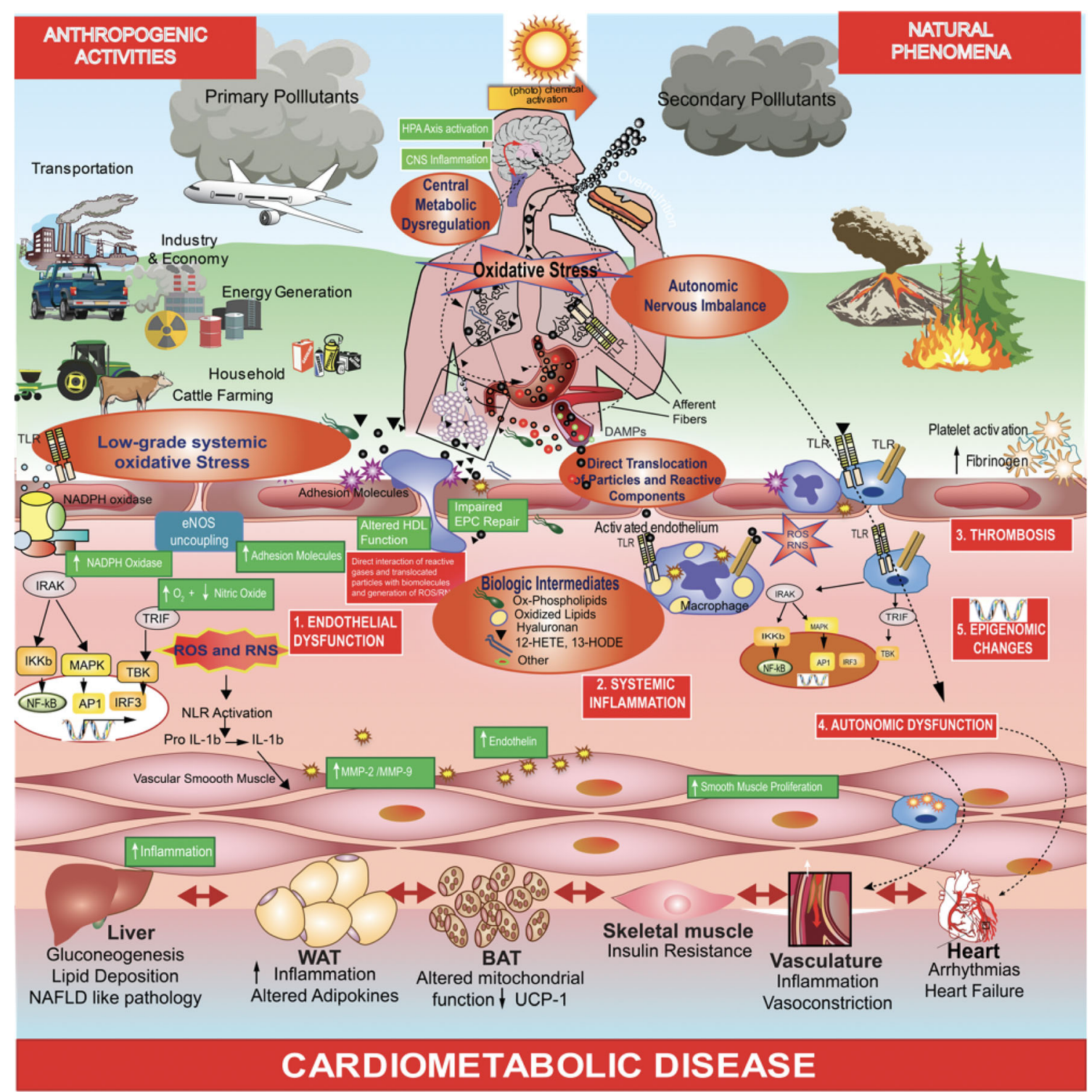

Fig. 3 Cellular and subcellular mechanisms involved in air pollutionmediated atherosclerosis. NLR, nod-like receptors; TLR, toll-like receptors; IRAK, interleukin-1 receptor-associated kinases; HPA axis, hypothalamic-pituitary-adrenal axis; CNS, central nervous system; DAMP, damage-associated molecular pattern; ROS, reactive oxygen species; RNS, reactive nitrogen species; EPC, endothelial progenitor cell; HDL, high-density lipoprotein; eNOS, endothelial nitric oxide

and apolipoprotein E knockout $\left(\mathrm{ApoE}^{--}\right)$[53-55]. The effects of $\mathrm{PM}_{2.5}$ appear to be comparable to those of secondhand smoke, at least in one study [56]. Atherosclerosis progression in susceptible models is characterized by an increase in innate immune response, extensive protein nitration, and increased lipid content (ESM Table 2). The effects of ultrafine particles appear to be stronger than those of $\mathrm{PM}_{2.5}$ [10]. In one study, 7-ketocholesterol (7-KC) content was increased in the plasma intermediate-density lipoprotein/low-density lipoprotein fraction and in aortic plaque, concomitant with progression of atherosclerosis and increased CD36 expression in plaque macrophages from $\mathrm{PM}_{2.5}$-exposed synthase; TRIF, TIR-domain containing adaptor inducing interferon- $\beta$; TBK, TANK-binding kinase 1; MAPK, mitogen-activated protein kinase; IKB, inhibitor of nuclear factor kappa-B kinase subunit beta; NF- $\mathrm{KB}$, nuclear factor kappa-light-chain-enhancer of activated B cells; $\mathrm{AP} 1$, activator protein 1 ; IRF3, interferon regulatory factor 3 ; IL-1 $\beta$, interleukin-1 beta; MMP, matrix metalloproteinase

mice. Macrophages isolated from $\mathrm{PM}_{2.5}$-exposed mice displayed increased uptake of oxidized lipids through a CD36-dependent pathway without alterations in their efflux capacity. Atherosclerosis progression in response to $\mathrm{PM}_{2.5}$ was attenuated by $\mathrm{CD} 36$ deficiency in hematopoietic cells suggesting a critical role for CD36 in uptake of 7-KC [51]. Figure 3 provides cellular and subcellular pathways relevant in atherosclerosis and have been previously summarized in other reviews [3, 38, 45]. Recent evidence supports widespread circadian disruption with $\mathrm{PM}_{2.5}$ exposure which may represent an integrated pathway for atherosclerotic risk [57]. 


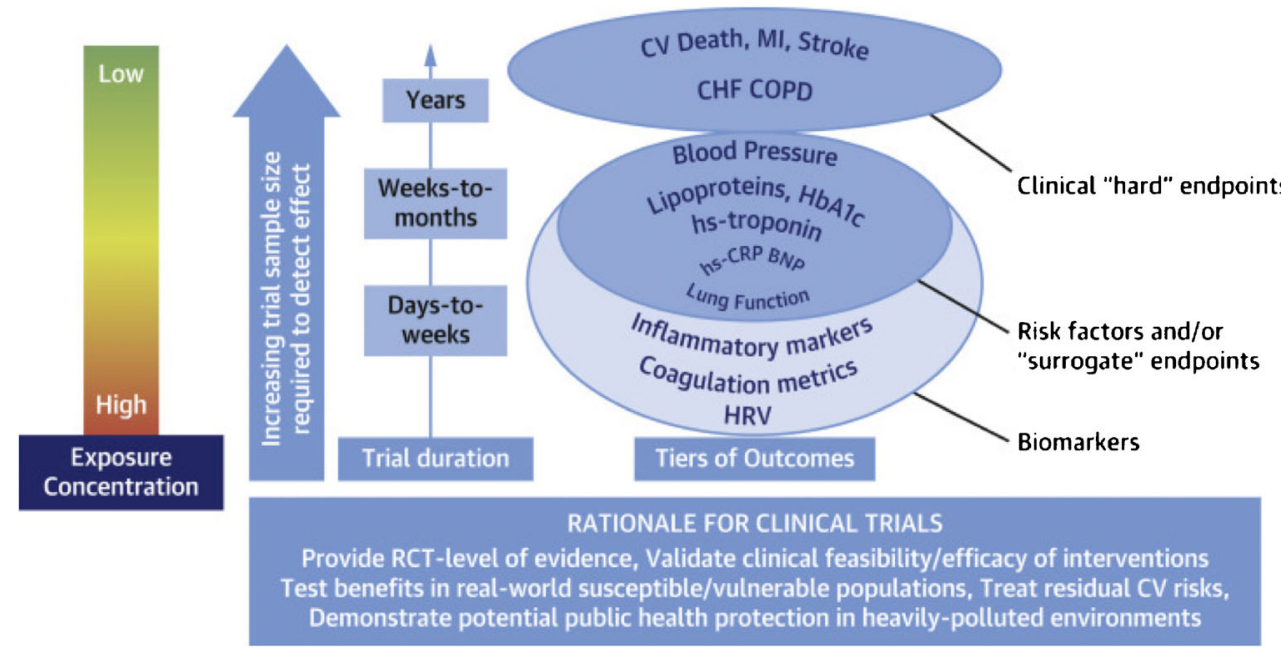

Fig. 4 Rationale for clinical trials of the cardiovascular effects of reductions in fine particulate air pollution. The purpose of randomized trials is to provide RCT-level evidence and validate feasibility and efficacy of interventions, and to test benefits in real-world susceptible/ vulnerable populations. CHF, congestive heart failure; COPD, chronic obstructive pulmonary disease; CV, cardiovascular; HbA1c, hemoglobin A1c; HRV, heart rate variability; hs, high sensitivity; MI, myocardial infarction; RCT, randomized controlled trial (with permission

\section{What Are the Unanswered Questions in Air Pollution-Mediated Atherosclerosis?}

There has indeed been an immense amount of understanding on air pollution-mediated cardiovascular events through careful animal experiments in susceptible models and in well-designed mechanistic studies in humans that have corroborated epidemiologic findings. The mechanistic evidence is supportive of a general paradigm of pro-atherogenic effects much akin to other conventional risk factors and employing stereotypic pathways of oxidant stress, vascular inflammation, and atherosclerosis progression [3]. Despite these advances, there still continues to remain multiple questions that could further advanced our understanding. From a compositional perspective, the role of specific components of air pollution that are most pro-atherogenic is important to address. This may help identify sources of air pollution that are higher priorities. The role of specific cellular components of inflammation including the role of adaptive immunity is not yet completely understood. Gut-derived mediators and the role of the central nervous system in modulating air pollution-mediated inflammation are not understood [58]. Finally, there is a need to understand homeostatic pro-resolution pathways that are operational in response to air pollution that could be bolstered by dietary or therapeutic manipulation to mitigate air pollution effects [38].

From a clinical perspective, there is a need for clinical trials that demonstrate benefit of air pollution reduction on major adverse cardiovascular events $[35,36]$. Such a trial would be hugely beneficial from a societal perspective. A recently concluded National Institutes of Health workshop identified 4 main from Newman JD, Bhatt DL, Rajagopalan S, Balmes JR, Brauer M, Breysse PN, Brown AGM, Carnethon MR, Cascio WE, Collman GW, Fine LJ, Hansel NN, Hernandez A, Hochman JS, Jerrett M, Joubert BR, Kaufman JD, Malik AO, Mensah GA, Newby DE, Peel JL, Siegel J, Siscovick D, Thompson BL, Zhang J and Brook RD. Cardiopulmonary impact of particulate air pollution in high-risk populations: JACC stateof-the-art review. J Am Coll Cardiol. 2020;76:2878-2894 [37])

categories of issues for evaluation to inform an air pollution intervention trial [37]. The workshop further expounded on the clinical trial design considerations including populations, sample size, trial duration, exposure considerations, and potential interventions (Fig. 4).

Supplementary Information The online version contains supplementary material available at https://doi.org/10.1007/s11883-021-00958-9.

\section{Declarations}

Conflict of Interest None of the authors has conflicts of interest pertinent to the contents of this manuscript.

Human and Animal Rights and Informed Consent This article does not contain any studies with human or animal subjects.

\section{References}

Papers of particular interest, published recently, have been highlighted as:

- Of importance

•- Of major importance

1. Brook RD, Rajagopalan S, Pope CA, Brook JR, Bhatnagar A, Diez-Roux A, et al. Particulate matter air pollution and cardiovascular disease. An update to the scientific statement from the American Heart Association. Circulation. 2010;121: 2331-78. 
2. Varga Z, Flammer AJ, Steiger P, Haberecker M, Andermatt R, Zinkernagel A, et al. Electron microscopy of SARS-CoV-2: a challenging task - Authors' reply. Lancet. 2020;395:e100.

3. Bevan GH, Al-Kindi S, Brook RD, Münzel T, Rajagopalan S. Ambient air pollution and atherosclerosis: insights into dose, time, and mechanisms. Arterioscler Thromb Vasc Biol. 2020;41:628-37.

4. Rajagopalan S, Al-Kindi SG, Brook RD. Air pollution and cardiovascular disease. J Am Coll Cardiol. 2018;72:2054-70.

5. EPA. NAAQS Table. 2021.

6.• Burnett R, Chen H, Szyszkowicz M, Fann N, Hubbell B, Pope CA, et al. Global estimates of mortality associated with long-term exposure to outdoor fine particulate matter. Proc Natl Acad Sci. 2018;115:9592-7 The authors utilize a multitude of studies of outdoor exposure cohorts to generate an integrated exposure model with the finding that the relationship between $\mathbf{P M}_{2.5}$ and mortality is near linear at any level.

7. Smith KR, Jerrett M, Anderson HR, Burnett RT, Stone V, Derwent $\mathrm{R}$, et al. Public health benefits of strategies to reduce greenhousegas emissions: health implications of short-lived greenhouse pollutants. Lancet. 2009;374:2091-103.

8. de Souza A, Guo Y, Pav HG, Fernandes WA. Effects of air pollution on disease respiratory: structures lag. Health. 2014;2014.

9. Silverman RA, Ito K. Age-related association of fine particles and ozone with severe acute asthma in New York City. J Allergy Clin Immunol. 2010;125:367-373.e5.

10. Araujo JA, Barajas B, Kleinman M, Wang X, Bennett BJ, Gong $\mathrm{KW}$, et al. Ambient particulate pollutants in the ultrafine range promote early atherosclerosis and systemic oxidative stress. Circ Res. 2008;102:589-96.

11. Daellenbach KR, Uzu G, Jiang J, Cassagnes L-E, Leni Z, Vlachou $\mathrm{A}$, et al. Sources of particulate-matter air pollution and its oxidative potential in Europe. Nature. 2020;587:414-9.

12. Delfino RJ, Sioutas C, Malik S. Potential role of ultrafine particles in associations between airborne particle mass and cardiovascular health. Environ Health Perspect. 2005;113:934-46.

13. Transportation USDo. Bureau of Transportation Statistics. In: NHTS 2001 Highlights Report; 2003.

14. Clay K, Muller NZ. Recent increases in air pollution: evidence and implications for mortality. In: National Bureau of Economic Research Working Paper Series; 2019. No. 26381.

15. Pope CA 3rd, Dockery DW. Health effects of fine particulate air pollution: lines that connect. J Air Waste Manage Assoc. 2006;56: 709-42.

16. Lu F, Xu D, Cheng Y, Dong S, Guo C, Jiang X, et al. Systematic review and meta-analysis of the adverse health effects of ambient PM2.5 and PM10 pollution in the Chinese population. Environ Res. 2015;136:196-204.

17. Krewski D, Jerrett M, Burnett RT, Ma R, Hughes E, Shi Y, et al. Extended follow-up and spatial analysis of the American Cancer Society study linking particulate air pollution and mortality. Res Rep Health Eff Inst. 2009;140:5-114 discussion 115-36.

18. Crouse DL, Peters PA, van Donkelaar A, Goldberg MS, Villeneuve $\mathrm{PJ}$, Brion $\mathrm{O}$, et al. Risk of nonaccidental and cardiovascular mortality in relation to long-term exposure to low concentrations of fine particulate matter: a Canadian national-level cohort study. Environ Health Perspect. 2012;120:708-14.

19. Liang F, Liu F, Huang K, Yang X, Li J, Xiao Q, et al. Long-term exposure to fine particulate matter and cardiovascular disease in China. J Am Coll Cardiol. 2020;75:707-17.

20. Pope CA 3rd, Muhlestein JB, May HT, Renlund DG, Anderson JL, Horne BD. Ischemic heart disease events triggered by short-term exposure to fine particulate air pollution. Circulation. 2006;114: 2443-8.

21. Mustafić H, Jabre P, Caussin C, Murad MH, Escolano S, Tafflet M, et al. Main air pollutants and myocardial infarction: a systematic review and meta-analysis. Jama. 2012;307:713-21.
22. Fu P, Guo X, Cheung FMH, Yung KKL. The association between PM2.5 exposure and neurological disorders: a systematic review and meta-analysis. Sci Total Environ. 2019;655:1240-8.

23. Shah AS, Langrish JP, Nair H, McAllister DA, Hunter AL, Donaldson $\mathrm{K}$, et al. Global association of air pollution and heart failure: a systematic review and meta-analysis. Lancet. 2013;382: 1039-48.

24. Ward-Caviness CK, Weaver AM, Buranosky M, Pfaff ER, Neas LM, Devlin RB, et al. Associations between long-term fine particulate matter exposure and mortality in heart failure patients. $J \mathrm{Am}$ Heart Assoc. 2020;9:e012517.

25. Bevan GH, Freedman DA, Lee EK, Rajagopalan S, Al-Kindi SG. Association between ambient air pollution and county-level cardiovascular mortality in the United States by Social Deprivation Index. Am Heart J. 2021;235:125-31.

26. Bell ML, Ebisu K. Environmental inequality in exposures to airborne particulate matter components in the United States. Environ Health Perspect. 2012;120:1699-704.

27. Hystad P, Larkin A, Rangarajan S, Al Habib KF, Avezum Á, Calik KBT, et al. Associations of outdoor fine particulate air pollution and cardiovascular disease in $157 \& \# \times 2008 ; 436$ individuals from 21 high-income, middle-income, and low-income countries (PURE): a prospective cohort study. Lancet Planetary Health. 2020;4:e23545 The findings from this study indicate the strong and consistent relationship between fine particulate matter and cardiovascular disease in communities around the world, regardless of income.

28. Lim CC, Hayes RB, Ahn J, Shao Y, Silverman DT, Jones RR, et al. Long-term exposure to ozone and cause-specific mortality risk in the U.S. Am J Respir Crit Care Med. 2019;200:1022-31.

29. Lippmann M, Chen L-C, Gordon T, Ito K, Thurston GD. National Particle Component Toxicity (NPACT) Initiative: integrated epidemiologic and toxicologic studies of the health effects of particulate matter components. Res Rep Health Eff Inst. 2013;177:5-13.

30. Ostro B, Hu J, Goldberg D, Reynolds P, Hertz A, Bernstein L, et al. Associations of mortality with long-term exposures to fine and ultrafine particles, species and sources: results from the California Teachers Study Cohort. Environ Health Perspect. 2015;123:54956.

31. Thurston GD, Burnett RT, Turner MC, Shi Y, Krewski D, Lall R, et al. Ischemic heart disease mortality and long-term exposure to source-related components of US fine particle air pollution. Environ Health Perspect. 2015;124:785-94.

32. Kapoor K, Cainzos-Achirica M, Nasir K. The evolving role of coronary artery calcium in preventive cardiology 30 years after the Agatston score. Curr Opin Cardiol. 2020;35:500-7.

33. Kaufman JD, Adar SD, Barr RG, Budoff M, Burke GL, Curl CL, et al. Association between air pollution and coronary artery calcification within six metropolitan areas in the USA (the Multi-Ethnic Study of Atherosclerosis and Air Pollution): a longitudinal cohort study. Lancet. 2016;388:696-704.

34. Y Yang S, Lee S-P, Park J-B, Lee H, Kang S-H, Lee S-E, et al. PM2.5 concentration in the ambient air is a risk factor for the development of high-risk coronary plaques. Eur Heart J Cardiovasc Imaging. 2019;20:1355-64 This cohort study examines the relationship between ambient air pollution exposure and the development of unstable plaque morphology by computed tomography angiography providing an important link between ambient air pollution exposure and cardiovascular events.

35. Brook RD, Newby DE, Rajagopalan S. Air pollution and cardiometabolic disease: an update and call for clinical trials. Am J Hypertens. 2017;31:1-10.

36. Brook RD, Newby DE, Rajagopalan S. The global threat of outdoor ambient air pollution to cardiovascular health: time for intervention. JAMA Cardiol. 2017;2:353-4. 
37. Newman JD, Bhatt DL, Rajagopalan S, Balmes JR, Brauer M, Breysse PN, et al. Cardiopulmonary impact of particulate air pollution in high-risk populations: JACC state-of-the-art review. $J$ Am Coll Cardiol. 2020;76:2878-94.

38. Gangwar RS, Bevan GH, Palanivel R, Das L, Rajagopalan S. Oxidative stress pathways of air pollution mediated toxicity: recent insights. Redox Biol. 2020;34:101545.

39. Munzel T, Gori T, Al-Kindi S, Deanfield J, Lelieveld J, Daiber A, et al. Effects of gaseous and solid constituents of air pollution on endothelial function. Eur Heart J. 2018;39:3543-50.

40. Mills NL, Tornqvist H, Gonzalez MC, Vink E, Robinson SD, Soderberg S, et al. Ischemic and thrombotic effects of dilute diesel-exhaust inhalation in men with coronary heart disease. $N$ Engl J Med. 2007;357:1075-82.

41. O'Toole TE, Hellmann J, Wheat L, Haberzettl P, Lee J, Conklin DJ, et al. Episodic exposure to fine particulate air pollution decreases circulating levels of endothelial progenitor cells. Circ Res. 2010;107:200-3.

42. Haberzettl P, Lee J, Duggineni D, McCracken J, Bolanowski D, O'Toole TE, et al. Exposure to ambient air fine particulate matter prevents VEGF-induced mobilization of endothelial progenitor cells from the bone marrow. Environ Health Perspect. 2012;120: 848-56.

43. Goto Y, Ishii H, Hogg JC, Shih $\mathrm{CH}$, Yatera $\mathrm{K}$, Vincent $\mathrm{R}$, et al. Particulate matter air pollution stimulates monocyte release from the bone marrow. Am J Respir Crit Care Med. 2004;170:891-7.

44. Kampfrath T, Maiseyeu A, Ying Z, Shah Z, Deiuliis JA, Xu X, et al. Chronic fine particulate matter exposure induces systemic vascular dysfunction via NADPH oxidase and TLR4 pathways. Circ Res. 2011;108:716-26.

45. Munzel T, Sorensen M, Gori T, Schmidt FP, Rao X, Brook FR, et al. Environmental stressors and cardio-metabolic disease: part IImechanistic insights. Eur Heart J. 2016:ehw294.

46. Pope CA 3rd, Hansen ML, Long RW, Nielsen KR, Eatough NL, Wilson WE, et al. Ambient particulate air pollution, heart rate variability, and blood markers of inflammation in a panel of elderly subjects. Environ Health Perspect. 2004;112:339-45.

47. Ruckerl R, Ibald-Mulli A, Koenig W, Schneider A, Woelke G, Cyrys J, et al. Air pollution and markers of inflammation and coagulation in patients with coronary heart disease. Am J Respir Crit Care Med. 2006;173:432-41.

48. Eze IC, Hemkens LG, Bucher HC, Hoffmann B, Schindler C, Kunzli N, et al. Association between ambient air pollution and diabetes mellitus in Europe and North America: systematic review and meta-analysis. Environ Health Perspect. 2015;123:381-9.
49. Zeka A, Sullivan JR, Vokonas PS, Sparrow D, Schwartz J. Inflammatory markers and particulate air pollution: characterizing the pathway to disease. Int J Epidemiol. 2006;35:1347-54.

50. Liu C, Xu X, Bai Y, Wang TY, Rao X, Wang A, et al. Air pollutionmediated susceptibility to inflammation and insulin resistance: influence of CCR 2 pathways in mice. Environ Health Perspect. 2014;122:17-26.

51. Rao X, Zhong J, Maiseyeu A, Gopalakrishnan B, Villamena FA, Chen L-C, et al. CD36-dependent 7-ketocholesterol accumulation in macrophages mediates progression of atherosclerosis in response to chronic air pollution exposure. Circ Res. 2014;115:770-80.

52. Yin F, Lawal A, Ricks J, Fox JR, Larson T, Navab M, et al. Diesel exhaust induces systemic lipid peroxidation and development of dysfunctional pro-oxidant and pro-inflammatory high-density lipoprotein. Arterioscler Thromb Vasc Biol. 2013;33:1153-61.

53. Suwa T, Hogg JC, Quinlan KB, Ohgami A, Vincent R, van Eeden SF. Particulate air pollution induces progression of atherosclerosis. $J$ Am Coll Cardiol. 2002;39:935-42.

54. Niwa Y, Hiura Y, Murayama T, Yokode M, Iwai N. Nano-sized carbon black exposure exacerbates atherosclerosis in LDL-receptor knockout mice. Circ J. 2007;71:1157-61.

55. Sun Q. Long-term air pollution exposure and acceleration of atherosclerosis and vascular inflammation in an animal model. JAMA. 2005;294:3003-10.

56. Chen LC, Quan C, Hwang JS, Jin X, Li Q, Zhong M, et al. Atherosclerosis lesion progression during inhalation exposure to environmental tobacco smoke: a comparison to concentrated ambient air fine particles exposure. Inhal Toxicol. 2010;22:449-59.

57. Palanivel R, Vinayachandran V, Biswal S, Deiuliis JA, Padmanabhan R, Park B, et al. Exposure to air pollution disrupts circadian rhythm through alterations in chromatin dynamics. iScience. 2020;23:101728.

58. Dujardin CE, Mars RAT, Manemann SM, Kashyap PC, Clements NS, Hassett LC, et al. Impact of air quality on the gastrointestinal microbiome: a review. Environ Res. 2020;186:109485.

59. Institute for Health Metrics and Evaluation (IHME). GBD Compare. Seattle, WA: IHME, University of Washington, 2015. Available from http://vizhub.healthdata.org/gbd-compare. (Accessed February $12^{\text {th }}, 2021$ )

Publisher's Note Springer Nature remains neutral with regard to jurisdictional claims in published maps and institutional affiliations. 